Peer Reviewed Article Vol.3(2) September 2001

\title{
Current standards for an effective portal application in an enterprise with specific reference to Woolworths
}

\author{
Sharon van Biljon \\ B2bafrica (Pty) Ltd \\ sharon.vbiljon@b2bafrica.com
}

\section{Contents}

1. Introduction

2. Case study

3. What is a portal?

4. Need for portals

5. Portal planning

6. Future

7. Conclusion

8. References

\section{Introduction}

Over the past couple of years, hundreds of vendors incorporated the concept of 'portal' into their marketing strategies (Ovum 2000). This portal consciousness seems to have made light of Knowledge Management (KM) issues for the time being. Prominent Internet portals such as Yahoo succeeded in creating structures for facilitating growth and increasing Internet usefulness. Yahoo and others make provision for structure, layout and navigation of documents. A standardised format is used (consistent with most networked computers) with searchable directories established for Web sites and categorised by topic (Traffick: the guide...). These same principles apply to an intranet on a much smaller scale.

Lacking Internet directories, intranet enthusiasts built large numbers of corporate sites while disregarding information structures, leaving behind 'messy collection[s] of disconnected Websites behind a firewall' (Globe 2000). The portal strategy of Woolworths, a retailer, will be used as a case study to determine how effective its information access is to users. Comments will be made on its strategy as compared to current global standards.

\section{Case Study: Woolworths (SA) intranet Strategy}

The 'Strategy to implement the Woolies intranet' (Casarin 1999) and a dissertation by its intranet manager, Paul Casarin, entitled 'The impact of information technology on knowledge creation in Woolworths', were used as corporate documents for this research. The first provided input on intranet planning. The second provided context on the operations of the 
enterprise. As it was clear that Woolworths focused on knowledge as a key business ingredient, it came as no surprise that they chose a knowledge portal as part of a KM strategy to 'facilitate' its creation and use.

\section{What is a portal?}

\subsection{Definitions}

According to PriceWaterhouseCoopers (PWC), portals will end the current practice of mirroring existing information silos onto an intranet and contribute to the growth of intranets as sources of aggregation, community and efficiency (Mello, 1999).

(Woolworths: The author noticed a similar interpretation by Woolworths, despite the PWC emphasis on e-commerce and a Woolworths emphasis on personalization of content).

\subsection{Types}

The author identified twelve different types of portals which may be divided into three main categories of importance, namely:

- Enterprise portals that deliver corporate information;

- knowledge portals that support knowledge worker roles (Ovum 2000) and integrate internal and external information suitable to the enterprise (Mello 1999); and

- workspace portals that provide an integrated form of access to all information resources required by a user (Ovum 2000).

(Woolworths: Woolworths identified its need for a knowledge portal in its first introductory sentence, complying with the requirement that planners should know exactly what it is they want. The Woolworths strategy places a high value on knowledge, 'Enterprise portals have become a key technology enabler to implement KM strategies in organisations' (Casarin 2000.)

\subsection{Criteria for success}

Although there are no standards governing portal design, certain requirements have proven helpful to distinguish between successful and unsuccessful portals. Ovum names three success factors that are prime indicators to see whether a portal would be successful or not, namely:

- Content (content should be relevant, updated and useful);

- community (identify the target community to evangelize portal messages; the community has shared interests, objectives and purposes; they communicate and interact); and

- commerce (daily attention of users) (Ovum 2000).

(Woolworths: Relevant content and growth are primary elements mentioned by Woolworths. It places a high value on community portal use. It has to capture and retrieve company information easily. Evangelising the portal message is also important to Woolworths as its intranet benefits have to be 'sold' in the enterprise. The community was asked to name the intranet, which turned out aptly to be Imbizo [Place of Sharing]. It is very much a community portal. Enterprise matters are discussed, ideas generated and issues resolved while the element of having fun is nurtured. In this way, knowledge sharing is 
Other related success factors are the following:

- Ease of use: Enterprise portals have to accommodate almost all of the target audience transcending location. (Woolworths: The strategy is aligned with this idea as all stakeholders have to have access to the Imbizo.)

- Wide access: Enterprise portals should provide broad access to both structured and unstructured information from a variety of sources, including metadata to enable users to find and understand information. Having access to the same type of information, chances are users will 'speak the same type of language' (Wiseth 1999; Wreden 2000). (Woolworths: Wide access to information is what Imbizo aims at. Specific mention is made of capturing 'structured and unstructured information from diverse sources', bearing in mind its focus is a knowledge portal.)

- Dynamism: Enterprise portals need to be broad and deep (functionally speaking) to enable users to search the taxonomy, publish documents, submit queries and find information (Wiseth 1999). A viable search system is a critically important aspect of a portal (Cain et al. 2000). (Woolworths: Imbizo captures contributions by its users with dynamism. It also mentions its search engine capability pertinently to enable relevant searches.)

- Flexibility: An application programming interface (API) should be incorporated in the enterprise portal to allow an easy integration of additional applications and data sources onto the intranet. Interactivity should be possible (Queck 1999) to allow users to publish their own work and to determine their security levels (Eckerson 1999). (Woolworths: Disparate (back-end) systems are designed to integrate, in line with this view.)

- Collaboration: Users should be able to use e-mail, participate in threaded discussions, create new folders and set up access control (Wiseth 1999). Collaboration is also important when existing knowledge is used to create new knowledge (Queck 1999).

- Customization: Users should be able to customize an enterprise portal to suit their information needs, starting with a pre-configured look and feel, sources and security of the enterprise portal itself (Wiseth 1999). (Woolworths: Presenting information 'in the format appropriate for all stakeholders' is not the same as personalising the portal. In this sense, the strategy seems somewhat rigid and not directed towards customization.)

- Pro-active: An enterprise portal alerts users by means of e-mail pagers when new (subscribed to) information becomes available. It provides business indicators in real time and makes provision for search engines that perform automated queries at scheduled times.

- Security: The enterprise is still in control at granular level. Data privacy and security are a given. (Woolworths: The security aspect was mentioned only briefly, so that one can only assume it would still be given enough attention from an enterprise and user point of view.)

- Scalability: The enterprise portal has to cope with large volumes of information flows when its back-end architecture is robust enough.

- Manageability: The enterprise portal should be manageable. The portal should be easy to build and to integrate with other resources, making provision for content 
management editors, general monitoring and fine tuning tools (Wiseth 1999; Eckerson 1999). A fragmented portal may become unmanageable (Queck 1999). It also needs governance. Roles and responsibilities should be defined in business and IT areas. (Woolworths: In the first year, the emphasis will be on ensuring that intranet content is manageable before proceeding gradually with the project.)

\section{Need for portals}

\subsection{Chaos to order}

Intranet chaos may be ascribed to a lack of vision, a taxonomy and intranet policies, procedures, standards, guidelines (PPSGs) and staff allocation. The end result is a messy concoction that is hardly an intranet. Remedies are sought either in a powerful search engine running over the mess, hoping it will be effective, or building a Web portal linking the many sites. The remaining option is to build a brand-new site based on prioritised information cycles with document management (Globe 2000). Only the latter option will raise the stakes. Attention is then paid to a contribution that adds value to top line of business to enhance revenues, improve customer service and quality. Top line growth is one of the key drivers behind the current enthusiasm for portals (Microsoft).

(Woolworths: The retailer seemed to emphasize the bottom line cost savings factor such as printing costs. Financial prudence could have been a realistic justification, as well as convincing top management of the viability of the project. In all, Woolworths played both sides of the card [increased sales and reduction in costs].)

\subsection{Information overload}

The sheer volume of information in an enterprise becomes daunting, (GartnerGroup) so that enterprises are using intranet portals to provide structure and organization to their data on the road to knowledge.

\subsection{Benefits}

Improving top line of business seems to be the main benefit of a portal. As IT spending is no longer regarded as a cost-saving strategy in itself (Mello, 1999) and profitability and productivity are unrelated, the focus has shifted to KM as such a contributor. 'We're moving into a new phase now where instead of cost savings as your business case justification, it's competitive advantage' (PWC). Enterprises need to be effective and make money. Enterprise portals are important contributors to top line business, closing gaps between systems and communities (Mello 1999).

\subsection{Knowledge management}

Portals are regarded by enterprises such as PWC as an 'access route' to KM. They are even critically important to KM in an enterprise (Phifer et al. 1998).

\section{Portal planning}

Not everyone needs the same type of information though (Wiseth 1999). 'Build-it-and-theywill-come' is obsolete thinking. Enterprise portals provide relevant and intuitive access to 
applications and information (Wiseth 1999) in a structured way. If an intranet is created without strong organising principles, it will inundate the user with information. A corporate portal should steer across currents of information to find exactly what the users are looking for (Queck 1999). In all, planning has to be realistic (Rutherford 2000).

(Woolworths: The approach to Imbizo was realistic as it followed a phased implementation over three years. It also reviewed its progress after the first year before continuing.)

According to the Meta Group, three steps govern portal planning projects:

- Determining business requirements

- Identifying information sources

- Analysing business impact.

(Woolworths: Woolworths wants to use Imbizo both to enhance its image and as an ongoing reflection of its dedication to service, value and quality.)

Portal planners should kick off by establishing what business wants and needs, by cataloguing its information repositories and by documenting end results. This information should be committed to a blueprint to explain exactly the reasons why a portal will be built in an enterprise.

(Woolworths: 'Strategy to implement the Woolies intranet' is the blueprint of the enterprise. It is not easy compiling the blueprint, so, the fact that is has been finalised before it was implemented deserves an accolade.)

From the start, planners have to know what portal type is needed. The functions and services of a knowledge portal form the main difference between a corporate and a knowledge portal. A knowledge portal is the result of an intranet-based KM architecture, marking the transition from a corporate portal (with a user interface) to a portal (with a collective interface). The requirements for the knowledge portal will be:

- User friendliness

- Integration with a wide range or services and applications

- Flexible and quickly adaptable collaborative environment (Woods and Sheina 1999).

The value of a portal in a KM infrastructure is largely reliant on its design. It should blend information with knowledge in a complex process of integration of information internal and external to the enterprise that results in corporate intelligence.

(Woolworths: Imbizo has linked seven 'portals' that cover its retail business and related services (Casarin 2000). It was impossible to establish whether the seven portals were indeed icons on the portal page. These could be vertical portals to accommodate the nature of its business. Even at the risk of postulating, the intranet manager talks about 'linked' (vertical) portals with the enterprise main portal. Planners have to decide whether to incorporate these vertically into the portal structure.)

Communities in an enterprise justify the existence of vertical portals because certain communities have specific requirements that are too specialised to integrated into a bigger whole. In time, a demand for the information delivered by them will alter their focus from vertical to horizontal. There is no denying that it is preferable to have one point of entry to the knowledge of an enterprise with an overarching taxonomy and icons that make these smaller communities accessible. Incorporating smaller communities into the overall planning ensures that they are drawn into a structured whole where standardised policies and 
procedures are followed (Queck 1999).

(Woolworths: The Imbizo Web Council supports the policies and standards of its intranet as it was mentioned. The Council appears to be keen to prevent its site lapsing into anarchy and chaos.)

Microsoft believes that strategy is the key to planning ahead and a 'must' for success in a learning organization. In $76 \%$ of case studies conducted by Teltech, managers who had invested in an advance planning strategy could boast of a project that had a high impact on their enterprises.

(Woolworths: One may assume that the Imbizo portal planners gave their portal project due consideration when providing for a three year portal project plan in its strategy.)

Planners should also consider what the scope would be. Microsoft contends that a KM portal will need constant nurturing (maintenance) (Mello 1999). It is critical to obtain ongoing feedback from the community it serves in order to maintain a portal successfully (Cain et al. 2000).

(Woolworths: Woolworths makes ample provision for nurturing its portal by the appointment of a Web Council that meets quarterly to monitor its implementation strategy. It regards feedback on current and future requirements as important.)

Including the community is a vital aspect of the success of a portal. This can be done by way of change management efforts (user training).

(Woolworths: Users will be trained to develop Web pages in a simple manner (as recommended in this paper.)

People play a primary role in the success of portal projects. By engaging staff in community building and by assuming motivational roles in the creation of a knowledge base, members of that community have to understand the benefits that are in store for them. Users should be involved in the entire life cycle of information of the portal and be rewarded for that.

(Woolworths: Users are identified as sources of specific content and expertise in line with their strategy. No mention was made rewarding knowledge sharing efforts.)

\subsection{Role players}

There is no clear-cut answer as to whether an intranet steering committee should be involved in planning a portal. Jakob Nielsen, a Web usability expert, contends that small specialist teams are an option (Rutherford 2000). Corporations like Motorola are steering clear of IT people. However, anyone who owns, collects and disseminates content are welcome participants (Rutherford 2000).

(Woolworths: Not only is Woolworths intent on small teams designing its portal [core, technical and line of business], but it supports the global trend of moving away from IT specialists to plan information strategy. IT was not the core function of their portal design team, but portal design in itself was. Ironically though, Woolworths chose to appoint its IT Director to champion the project [Casarin 2000].)

\subsection{Goals}

One of the primary goals of a portal is to lure heavy traffic to a site. The more visits, the 
better attention the portal can capture to increase its value. If the user is not able to navigate the portal with ease, the user will never return unless the portal content is up to date, relevant, useful and has a certain intrinsic value (Ovum 2000). Once heavy traffic has been achieved, users should be encouraged to return regularly (retention).

(Woolworths: Its portal planners managed to emulate these two basic tenets of portal planning with uncanny surety. Not only did they focus on publishing content, but they also lured users and encouraged them to use it. Woolworths wished to build and maintain relationships with its community that is completely in line with what Ovum suggested. In a sense, Woolworths touched on the expected results of sharing knowledge among members of its interactive online community when it mentions 'productivity gains'. Within a year, it expects new products and services. This supports the fundamental principle of a knowledge portal that nurtures innovation among users by knowledge sharing.)

\subsection{Infrastructure}

Portals are generally based on eight areas of functionality, as mentioned by Ovum and Meta Group mention namely personalization, search and navigation, integration, push, collaboration and groupware, task automation and workflow, applications and infrastructure.

(Woolworths: Every functionality mentioned by the Gartner Group has been incorporated into the Woolworths strategy document.)

Navigation functionality has to be simple and robust. The only way to achieve this, is to organize content in easily searchable categories (taxonomy) with a powerful search engine handling queries. Users should be encouraged to publish portal information themselves (Queck 1999).

(Woolworths: Users will be trained to develop Web pages in a simple manner. An index page will be created and maintained for dissemination to the target audience.)

\subsection{Vendors}

Lately, vendors have discovered portals with such vigour that it has become difficult to see the real benefits. Oracle warns enterprises against implementing a variety of products from a wide range of vendors, each with a different focus to meet the needs of an enterprise (Woods and Sheina 1999).

(Woolworths: Woolworths refused to be lured into the vendor trap. They stated emphatically that they intended supporting only one vendor [Microsoft] because a viable integration of all products and services were critically important to them.)

\section{Future}

Expectations are high of the portal of the future, with some people believing it will become vital to business in future (Queck 1999). In future, it could be possible for a portal to insulate the user from having to know what his information sources are, to create the ability to extract information from an infinite variety of sources and to coordinate these to create a userfriendly logical front-end. This will enable the user to conduct all daily business from a single point of entry, namely the enterprise portal (Mello 1999). This means that planners will finally take users into consideration when designing the portal enterprise. The day is long gone when users were treated indifferently by technology, too. This attitude simply 
fostered chaos in the past (Mello 1999; Queck 1999). It seems as if personalised portals seem to be the users' retort to being ignored for so long.

In essence, users will be able to meta browse to extract suitable information by being able to select any information from existing Web content to build their own personalised start page. This activity frees users from a branded portal experience and its built-in boundaries (Harmon 2000). By implementing the blanket technology and information insight presented by a knowledge portal, staff will be able to gain most from disparate information repositories in a newly organised, effective and intuitive manner (Queck 1999). It was estimated that at least $80 \%$ of Fortune 500 companies will be pursuing and piloting portal projects during 2000 (Wreden 2000).

\section{Conclusion}

A portal could be likened to the contents page of a book. It is a first incisive glance at the content inside. It is also a moment of truth for author and user alike. If the user likes what he sees and continues to read, a certain relationship will be forged, especially if the book is well-presented, logical, useful and insightful, regardless of its static nature. By comparison, a portal has so many advantages over static content. If it is planned well from the outset, it may become a valuable asset to an enterprise. It was clear that the portal planning team at Woolworths was diligent and sophisticated enough to research portal design beforehand. This is evident in their lucid and realistic strategy that is characterised by its prudence without sacrificing creativity and enthusiasm. At the same time, their planners managed to couch the project firmly in the values of service and quality of the enterprise. Even the quality of the strategy document testifies to the service and quality espoused by the enterprise.

It was not easy to fault the thinking in the document, but the apparent lack of buy-in from top management (which could be construed wrongly) was one concern. The other was the apparent contradiction of the role of IT in the portal project. The strategy relegates IT people to a supporting role that is in line with accepted criteria for successful portal planning, yet an IT person was appointed as the project champion. All things being equal, there is more than enough reason to believe that Woolworths has built a quality portal for its community that will serve it well and add value to the enterprise.

\section{References}

1. Cain, M., Folger, D., Hickernell, T. and Roth, C. 2000. Meta Group Web \& Collaboration Strategies” 1st 2000 Trend Teleconference Transcript March 15, 2000: Enterprise Portals 2000: Strategies for Deployment. Meta group Inc. Stamford, CT.

2. Casarin, P. 2000. An African enterprise portal at WOOLWORTHS. Knowledge Management, 2(3):56-62.

3. Casarin, P. 1999. Strategy to implement the Woolies intranet.

4. Eckerson, W. 1999. Industry insight: 15 rules for enterprise portals. [Online]. Available WWW: http://www.oracle.com/oramag/oracle/99-Jul/4.

5. Globe, A. 2000. Intellectual ergonomics: an intranet diary. Knowledge Management, 3 (7):18-20.

6. Harmon, S. 2000. Next big thing for users: personal portals. [Online]. Available WWW: http://www.portalhub.com/story/08-2000/harmon.asp.

7. Mello, J.P. 1999. It's the content that counts. [Online]. Available WWW: 
http://www.microsoft.com/CIO/0999_km_print.html.

8. Ovum. 2000. Have you Heard... (152):1-2.

9. Ovum. 2000. Have you Heard... (024):1-2.

10. Phifer, G., Smith, D., Meehan, P., Terhune, A and Lombardo, D. 1998. A fresh look at the Internet: strategic analysis report. GartnerGroup.

11. Queck, C. 1999. Portal power - taming the corporate intranet. Knowledge Management, 1(4):32-36.

12. Rutherford, E. 2000. Is this any way to build an intranet? [Online]. Available WWW: http://cio.com/archive/040100_intranet_content.

13. Traffick: the guide to portals. [Online]. Available WWW: http://portalhub.com/story/07-2000-portalfaq.asp.

14. Wiseth, K. 1999. Portal power. [Online]. Available WWW: http://oracle.com/oramag/oracle/99-Nov/69ep.htm.

15. Woods, E. and Sheina, M. 1999. Ovum knowledge management: building the collaborative enterprise. Ovum Limited.London

16. Wreden, N. 2000. Enterprise portals: integrating information to drive productivity [Online]. Available WWW: http://beyond computingmag.com/archive/2000/02.

\section{Disclaimer}

Articles published in SAJIM are the opinions of the authors and do not necessarily reflect the opinion of the Editor, Board, Publisher, Webmaster or the Rand Afrikaans University. The user hereby waives any claim he/she/they may have or acquire against the publisher, its suppliers, licensees and sub licensees and indemnifies all said persons from any claims, lawsuits, proceedings, costs, special, incidental, consequential or indirect damages, including damages for loss of profits, loss of business or downtime arising out of or relating to the user's use of the Website.

ISSN 1560-683X

Published by InterWord Communications for the Centre for Research in Web-based Applications, Rand Afrikaans University 